\title{
Recurrent wheezing after respiratory syncytial virus infection in children under 3 years of age: a 1-year follow-up study
}

\section{Li Zhou ( $\square$ zhou1987117@126.com )}

Women And Children's Hospital

Jing Li

Women And Children's Hopital Of Ganzhou

Fang Hu

Women And Children's Hopital Of Ganzhou

Lin Zhang

Women's And Children's Hospital Of Jian

Hua Xiang

Women's And Children's Hospital Of Jian

Juan Ren

Women And Children's Hospital

Research

Keywords: infants; wheezing; RSV; follow-up study

Posted Date: August 24th, 2020

DOl: https://doi.org/10.21203/rs.3.rs-59435/v1

License: (1) This work is licensed under a Creative Commons Attribution 4.0 International License.

Read Full License 


\section{Abstract}

Background: Wheezing in infancy is very common. RSV infection can cause recurrent wheezing. The aim of this study was to explore the risk factors of recurrent wheezing in children under 3 years of age after RSV infection.

Methods $₫$ We chose children with initial wheezing before 3 years of age who were hospitalized for medical treatment. Wheezing frequency was determined by follow-up at 1 week, 1 month, 3 months, 6 months, and 1 year. Information such as birth status, age, sex, preterm, mode of delivery, birth order, eczema history, personal allergy history, family allergy history, passive smoking, and place of residence (urban/rural) was collected. Total serum IgE level, serum allergen testing, routine blood tests, C-reactive protein level, procalcitonin level, respiratory pathogens tests, sputum culture, chest radiography or computed tomography were performed in all patients. The correlation between each factor and wheezing recurrence was evaluated.

Results: A total of 259 children were included in the study. They were divided into single recurrence, multiple recurrences, and no recurrence groups. There were significant differences between the single recurrence and multiple recurrences groups in terms of personal allergy history, passive smoking, total serum IgE level, age, hospital stay duration, and wheezing duration $(p<0.05)$. The percentage of children with a personal allergy history in the multiple recurrences group was significantly higher than that of children in the single recurrence and no recurrence groups ( $p=0.031$ and 0.008 , respectively). The age of children in the multiple recurrences group was significantly lower than that of children in the single recurrence group $(p=0.000)$. The cost of re-hospitalization in the multiple recurrences group was significantly higher than that in the single recurrence and no recurrence groups $(p=0.000$ and 0.000 , respectively).

Conclusions: Children with a personal allergy history were more likely to have wheezing episodes. The frequency of wheezing in children under 3 years of age within 1 year of a respiratory syncytial virus infection was related to age. The younger the age at the time of the onset of wheezing, the more wheezing recurrences in the following year.

\section{Background}

About a third of infants experience at least 1 wheezing episode before 3 years of age, and half experience a wheezing episode by 6 years of age. However, not all infants who experience wheezing continue to wheeze. Almost a fifth of these infants suffer from recurrent wheezing in Latin American countries, indicating an important public health problem[1]. Viral infections are the most common cause of wheezing in infants and young children, with human respiratory syncytial virus (RSV) being the most common[2, 3]. RSV infection can cause irreversible lung damage and increase the incidence of chronic lung disease in adulthood[4]. Prospective epidemiologic studies of lower respiratory tract infections caused by RSV in early life have demonstrated subsequent asthma and airway hyper-responsiveness 
rates $25-80 \%$ greater than in uninfected controls up to 11 years later $[5,6]$. The clinical treatment of recurrent wheezing is difficult and has many influencing factors, greatly burdening families and society.

Allergen sensitization in early life is an important risk factor for the persistence of wheezing after 6 years of age, and it is positively correlated with the intensity of anaphylaxis. Other studies have shown that the incidence of wheezing may be related to multiple factors such as maternal conditions, personal fitness, and environmental factors[7, 8]. However, there are few follow-up studies on infant wheezing. In this study, children under 3 years of age were followed up for a year after an initial wheezing episode. The frequency and risk factors of recurrent wheezing were analyzed. Early intervention may reduce the incidence of recurrent wheezing and improve prognosis, which is beneficial to disease control, and it may greatly reduce future medical expenses and family burden.

\section{Methods}

\section{Study population}

We included children with an initial wheezing episode before 3 years of age who were hospitalized for medical treatment in the Maternal and Child Health Hospital in Ganzhou from January 2018 to March 2019. All children were tested for RSV infection only. We excluded those with cardiopulmonary dysplasia, gastroesophageal reflux, tuberculosis, laryngeal softening, mediastinal masses, immune deficiencies, and tracheal or bronchial foreign bodies.

\section{Data collection}

Information such as birth status, age, sex, preterm, mode of delivery, birth order, eczema history, personal allergy history, family allergy history, passive smoking, and place of residence (urban/rural) was collected. Total serum immunoglobulin E ( $\mathrm{lgE}$ ) level, serum allergen testing, routine blood tests, C-reactive protein level, procalcitonin level, testing for 11 antibodies against respiratory pathogens, nasopharyngeal aspirate testing, sputum culture, chest radiography or computed tomography, echocardiography, and color Doppler echocardiography were performed in all patients. The patients were followed up at 1 week, 1 month, 3 months, 6 months, and 1 year. In the first 3 visits, information was collected mainly through the family members of the sick child coming to the hospital. For the last 3 encounters, information was collected mainly by telephone. The follow-up information involved the duration of additional wheezing episodes, what induced the wheezing, re-hospitalization, duration of re-hospitalization, drug use, comorbidities, recurrence of wheezing, cost of re-hospitalization, etc.

\section{Statistical analyses}

Patients were divided into study group (recurrence group: single recurrence group, multiple recurrence group) and control group (no recurrence group).

SPSS 17.0 software was used for statistical analysis of clinical data. Counting data were described by cases and percentage. Categorical variables were compared by Chi-square test. F test was used for normal distribution between two groups, and non-parametric rank sum test was used for skewed 
distribution. Measurement data were expressed as mean \pm SD (normal distribution). Two independent sample tests were used for inter-group comparison. Non-normal distribution data were expressed as the median and inter-quartile range. When significant differences were identified, individual groups were compared using the Man-Whitney U-test. A p value of less than 0.05 was considered statistically significant.

\section{Results}

A total of 259 children were included in the study. There were 188 males and 71 females. The average age at the time of the initial wheezing episode was $8.91 \pm 7.71$ months. There were 152 urban residents (58.7\%). The average hospital stay duration was $6.31 \pm 2.43$ days. Among the 259 children, 147 experienced wheezing again within 1 year, and the recurrence rate was $56.8 \%$. Among these 147 children, $79(30.5 \%)$ had a single recurrence and $68(26.3 \%)$ had 2 or more recurrences.

In the single recurrence group, there were 53 males, 10 cases of premature delivery, 54 cases of natural childbirth, 45 urban residents, 11 patients with a family allergy history, and 3 patients with a personal allergy history. The average age at the time of the initial wheezing episode was $12.04 \pm 8.25$ months. The hospitalization duration ranged from 2 to 12 days, with an average of $6.42 \pm 2.2$ days. IgE levels fluctuated from 0 to $1372 \mathrm{IU} / \mathrm{mL}$, and the average IgE level was $123.13 \pm 257.61 \mathrm{IU} / \mathrm{mL}$. The duration of wheezing fluctuated from 1 to 37 days, with an average of $5.95 \pm 8.05$ days.

In the multiple recurrences group, there were 55 males, 9 cases of premature delivery, 45 cases of natural childbirth, 43 urban residents, 8 patients with a family allergy history, and 9 patients with a personal allergy history. The average age at the time of the initial wheezing episode was $7.71 \pm 7.03$ months. The hospitalization duration ranged from 2 to 18 days, with an average of $6.71 \pm 2.39$ days. IgE level fluctuated from 0 to $990 \mathrm{IU} / \mathrm{mL}$, and the average $\mathrm{IgE}$ level was $103.75 \pm 180.17 \mathrm{IU} / \mathrm{mL}$. The duration of wheezing fluctuated from 1 to 31 days, with an average of $6.44 \pm 6.19$ days.

The single recurrence and multiple recurrences groups were compared. There were no significant differences in terms of sex, place of residence, mode of delivery, premature delivery, or family allergy history between the 2 groups ( $p>0.05$ ). There were significant differences between the 2 groups in terms of personal allergy history, passive smoking, total serum IgE level, age, hospital stay duration, and wheezing duration $(p<0.05)$. The percentage of children with a personal allergy history in the multiple recurrences group was significantly higher than that of children in the single recurrence and no recurrence groups ( $p=0.031$ and 0.008 , respectively). The age of children in the multiple recurrences group was significantly lower than that of children in the single recurrence group $(p=0.000)$. The hospitalization duration for children with initial wheezing in the multiple recurrences group was significantly longer than that for children in the single recurrence and no recurrence groups ( $p=0.042$ and 0.016 , respectively). The cost of re-hospitalization in the multiple recurrences group was significantly higher than that in the single recurrence and no recurrence groups ( $p=0.000$ and 0.000 , respectively). This information is presented in Table. 
Table Comparison of each factor among three groups.

\begin{tabular}{|c|c|c|c|c|}
\hline & $\begin{array}{l}\text { a single recurrence } \\
\text { group } \square n=79 \square\end{array}$ & $\begin{array}{l}{ }^{\mathrm{b}} \text { multiple recurrences } \\
\text { group } \llbracket \mathrm{n}=68 \square\end{array}$ & $\begin{array}{c}{ }^{\mathrm{C}} \text { no } \\
\text { recurrence } \\
\text { group } \square \mathrm{n}=112 \square\end{array}$ & $\bar{P}$ \\
\hline With personal allergy history & 3 & 9 & 3 & $\begin{array}{l}\mathrm{Pab}=0.031 \\
\mathrm{Ph}=0.008\end{array}$ \\
\hline $\begin{array}{l}\text { With family allergy history } \\
\text { Birth order }\end{array}$ & $\begin{array}{c}11 \\
1.87 \pm 0.79 \square 1-5 \square\end{array}$ & $\begin{array}{c}8 \\
2.18 \pm 0.98 \square 1-6 \square\end{array}$ & $\begin{array}{c}12 \\
1.96 \pm 1.03 \square 1-\end{array}$ & $\begin{array}{c}\mathrm{P}=0.796 \\
\mathrm{Pab}=0.05\end{array}$ \\
\hline Age $\square$ months $\square$ & $12.04 \pm 8.25 \square 2-36 \square$ & $7.71 \pm 7.03 \square 1-34 \square$ & $\begin{array}{c}7.86 \pm 5.97 \square 1- \\
36 \square\end{array}$ & $\begin{array}{l}\mathrm{Pab}=0.000 \\
\mathrm{Pbc}=0.000\end{array}$ \\
\hline $\begin{array}{l}\text { Place of residence } \\
\text { (urban/rural) }\end{array}$ & 45 & 43 & 64 & $\mathrm{P}=0.675$ \\
\hline Preterm & 10 & 9 & 14 & $\mathrm{P}=0.084$ \\
\hline $\mathrm{Sex} \rrbracket \mathrm{man} \rrbracket$ & 53 & 55 & 80 & $\mathrm{P}=0.163$ \\
\hline $\begin{array}{l}\text { Mode of delivery } \\
\text { ¿Spontaneous Labor }\end{array}$ & 54 & 45 & 74 & $\mathrm{P}=0.94$ \\
\hline Passive smoking & 3 & 12 & 4 & $\begin{array}{l}\mathrm{Pab}=0.023 \\
\mathrm{~Pb}=0.008\end{array}$ \\
\hline Total serum IgE level $₫ \mathrm{IU} / \mathrm{ml}[\mathrm{c}$ & $\begin{array}{c}123.13 \pm 257.61 \square 0- \\
1372 \square\end{array}$ & $103.75 \pm 180.17 \square 0-990 \square$ & $\begin{array}{c}58.76 \pm 100.34 \\
\square 0-470 \square\end{array}$ & $\mathrm{Pbc}=0.012$ \\
\hline Hospital stay duration $\square$ days $\square$ & $6.42 \pm 2.2 \square 2-12 \square$ & $6.71 \pm 2.39 \square 2-18 \square$ & $\begin{array}{c}598 \pm 2.56 \square 1- \\
16 \square\end{array}$ & $\begin{array}{l}\mathrm{Pab}=0.042 \\
\mathrm{Pbc}=0.016\end{array}$ \\
\hline $\begin{array}{l}\text { Wheezing duration when } \\
\text { hospitalization } \square \text { days } \square\end{array}$ & $5.95 \pm 8.05 \square 1-37 \square$ & $6.44 \pm 6.19 \square 1-31 \square$ & $\begin{array}{c}5.1 \pm 8.33 \square 1- \\
66 \square\end{array}$ & $\begin{array}{l}\mathrm{Pab}=0.097 \\
\mathrm{Pac}=0.286 \\
\mathrm{Pbc}=0.003\end{array}$ \\
\hline $\begin{array}{l}\text { Cost of re-hospitalization } \\
\text { पyuan }\end{array}$ & $\begin{array}{c}2938.65 \pm 2009.887 \square 0- \\
8790 \square\end{array}$ & $\begin{array}{c}6987.14 \pm 4074.981 \square 0- \\
21680 \square\end{array}$ & 0 & $\begin{array}{l}\mathrm{Pab}=0.000 \\
\mathrm{Pac}=0.000 \\
\mathrm{Pbc}=0.000\end{array}$ \\
\hline
\end{tabular}

${ }^{\mathrm{a}}$ single recurrence group, ${ }^{\mathrm{b}}$ multiple recurrences, ${ }^{\mathrm{c}}$ no recurrence

\section{Discussion}

In recent years, there have been many reports on the correlation between RSV infection and infant wheezing. RSV is not only the main cause of early respiratory tract infection in infants, but it is also a main risk factor for infant wheezing[9]. RSV infection can cause airway inflammation and vasospasm in infants, leading to long-term airway hyper-responsiveness and recurrent wheezing. Severe RSV infection has repeatedly been associated with long-term complications, including impaired lung function, recurrent wheezing, and asthma. Because infant respiratory system development is not perfect, neither is immune system maturation, and early pathogen exposure can easily cause wheezing. The immunity acquired by RSV infection is not lasting. Bertrand suggested that interleukin (IL)-3 and IL-12p40 could be molecular predictors for recurrent wheezing due to RSV infection[10]. He presented a comprehensive cytokine and chemokine profile analysis in the upper and lower airways of infants with RSV bronchiolitis and identified key mediators directly associated with clinical outcomes within 3 years of patient follow-up. Acute bronchiolitis in infancy is considered a risk factor for recurrent wheezing in childhood. The present study assessed the prevalence of wheezing, the clinical manifestations and risk factors for recurrent wheezing during the first 3 years of life, and persistent wheezing beyond this age in children hospitalized as young infants with acute bronchiolitis. Hospitalization for acute bronchiolitis within the first 6 months of life is an independent risk factor for recurrent wheezing during the first 3 years of life[11]. Hosoki conducted a study of 99 Japanese patients with RSV-associated hospitalizations using questionnaires and follow-up surveys. He found that age on admission, atopic profile, history of continuous nocturnal cough before 
admission, gestational age, birth weight, hospital stay duration, perinatal abnormality, environmental tobacco smoke, parental allergy and asthma history, presence of siblings, and sibling allergy and asthma history were not associated with subsequent wheezing[12].

This study showed that infants with allergic constitution had a higher probability of frequent wheezing than infants with non-allergic constitution. Atopic constitution and infant wheezing have certain correlation. Allergenic sensitization is a main cause of wheezing[13]. RSV infection prevalence, eosinophil percentage, and serum eosinophil-derived neurotoxin levels are the predominant risk factors of wheezing and could therefore be used to predict recurrent wheezing in infants[14]. The risk factors for developing asthma by 6 years of age in children hospitalized for wheezing before 2 years of age are eosinophils in the blood, atopic dermatitis, elevated serum IgE levels and wheezing onset in early life. It has been suggested that the defining factor of childhood asthma is atopy[8]. A viral infection may aggravate an allergic reaction in some cases[15]. Martinez suggested that transient wheezing in young children is not associated with an atopic predisposition[16].

This study found that the recurrence of wheezing was related to age. The younger the age at the time of the initial wheezing episode, the more wheezing recurrences in the following year. Infants with RSV infection have a significantly higher risk of wheezing in the following year than those infected with other pathogens, and targeted antiviral therapy, especially in younger children, may reduce the risk of recurrent wheezing[17]. Matricardi showed that the incidence of wheezing declined with age[18]. Guo found that the number of wheezing episodes decreased significantly during the follow-up stage and that the age at the onset of wheezing was earlier in those with transient wheezing than in those with persistent wheezing[19]. The respiratory system gradually undergoes development with age, which may be an important reason for the decrease in the number of wheezing episodes[20].

\section{Conclusions}

This study found that personal allergy history and age were predictive of wheezing in infants within the year following an initial RSV infection, which helps to identify and predict the risk of recurrent wheezing in infants. Early intervention is available for infants and young children at high risk of recurrence. This study included a relatively small number of children, and the children were from a unit of our hospital; thus, there may be some case-selective bias. A multicenter prospective clinical study should be performed to further evaluate the risk factors of recurrent wheezing in infants and young children; this would provide more sufficient clinical evidence for the diagnosis, treatment, and prevention of recurrent wheezing in infants. In addition, because this study is a retrospective survey, bias in the collection of information due to memory bias is inevitable. Further, we were unable to assess patients' pulmonary function at the time of follow-up. We will therefore continue to follow them up and assess their lung function and changes in allergens that may be allergenic. Nevertheless, the results of this study still have high reference value for the management and prevention of infant wheezing.

\section{List Of Abbreviations}


Respiratory syncytial virus (RSV); Immunoglobulin E (IgE); Interleukin (IL)

\section{Declarations}

\section{Competing interests}

The authors have no conflict of interest to declare.

\section{Authors' contributions}

$\mathrm{L} Z$ and $\mathrm{J} R$ contributed to the concept and design of the study, analyzed and interpreted the data, and assisted in the critical writing. $J \mathrm{~L}$ and $\mathrm{F} \mathrm{H}$ helped to analysis statistic. $\mathrm{L} Z$ and $\mathrm{HX}$ contributed to the collection of clinical information. All authors read and approved the final manuscript.

\section{Ethics approval and consent to participate}

This study was approved by the Ethics and Research Council of Women and Children's hospital of Ganzhou, and signed consent was obtained from each child's parents or foster parents.

\section{Consent for publication}

All authors have read and approved the content, and agree to submit it for consideration for publication.

\section{Availability of data and materials}

The datasets supporting the conclusions of this article are included within the article.

\section{Acknowledgements}

We thank all the families for their enrollment in this study. We also thank the staff in the Department of Respiratory Medicine.

\section{No Funding}

\section{References}

1. Alvarez-Alvarez I,Niu H,Guillen-Grima F et al. Meta-analysis of prevalence of wheezing and recurrent wheezing in infants.[J] .Allergol Immunopathol (Madr), 2018, 46: 210-217.

2. Takeyama Aya,Hashimoto Koichi,Sato Masatoki et al. Clinical and epidemiologic factors related to subsequent wheezing after virus-induced lower respiratory tract infections in hospitalized pediatric patients younger than 3 years.[J] .Eur. J. Pediatr., 2014, 173: 959-66.

3. Valkonen $\mathrm{H}$, Waris $\mathrm{M}$, Ruohola $\mathrm{A}$ et al. Recurrent wheezing after respiratory syncytial virus or nonrespiratory syncytial virus bronchiolitis in infancy: a 3-year follow-up.[J] .Allergy, 2009, 64: 1359-65. 
4. Tai Andrew,Tran Haily,Roberts Mary et al. Outcomes of childhood asthma to the age of 50 years.[J] .J. Allergy Clin. Immunol., 2014, 133: 1572-8.e3.

5. Bont L,Steijn M,Van Aalderen W M C et al. Seasonality of long term wheezing following respiratory syncytial virus lower respiratory tract infection.[J] .Thorax, 2004, 59: 512-6.

6. Simões Eric A F,Carbonell-Estrany Xavier,Rieger Christian H L et al. The effect of respiratory syncytial virus on subsequent recurrent wheezing in atopic and nonatopic children.[J] .J. Allergy Clin. Immunol., 2010, 126: 256-62.

7. Owora Arthur H,Zhang Yijia: Childhood wheeze trajectory-specific risk factors: a systematic review and meta-analysis.[J] .Pediatr Allergy Immunol, 2020, doi:10.1111/pai.13313.

8. Brahim Errahmani M, Fellague Chebra K, Messaoudi Z: Multidimensional analysis of genetic background and environmental factors: Cases of atopy in asthmatic children. [J]. Arch Pediatr, 2020, doi:10.1016/j.arcped.2020.05.011.

9. Gu Ting, Gu Yueqin.Clinical study on respiratory virus infection and asthmatic attack in infants. [J]. Medical Information,2014, 27(23) 150-151.

10. Bertrand Pablo,Lay Margarita K,Piedimonte Giovanni et al. Elevated IL-3 and IL-12p40 levels in the lower airway of infants with RSV-induced bronchiolitis correlate with recurrent wheezing.[J] .Cytokine, 2015, 76: 417-423.

11. Rinawi Firas,Kassis Imad,Tamir Rina et al. Bronchiolitis in young infants: is it a risk factor for recurrent wheezing in childhood?[J] .World J Pediatr, 2017, 13: 41-48.

12. Hosoki Koa,Nagao Mizuho,Hiraguchi Yukiko et al. Factors related to recurrent wheezing after hospitalization with RSV infection with the children who were aged three years old or younger: a questionnaire survey.[J] .Arerugi, 2009, 58: 1513-20.

13. Wright $\mathrm{G}$ R,Howieson S,McSharry $\mathrm{C}$ et al. Effect of improved home ventilation on asthma control and house dust mite allergen levels.[J] .Allergy, 2009, 64: 1671-80.

14. Zhai Jia,Zou Yingxue,Liu Jie et al. Analysis of the predicting factors of recurrent wheezing in infants. [J] .Ital J Pediatr, 2019, 45: 19.

15. Kotaniemi-Syrjänen Anne,Reijonen Tiina M,Korhonen Kaj et al. Wheezing requiring hospitalization in early childhood: predictive factors for asthma in a six-year follow-up.[J] .Pediatr Allergy Immunol, 2002, 13: 418-25.

16. Martinez F D, Role of respiratory infection in onset of asthma and chronic obstructive pulmonary disease.[J] .Clin. Exp. Allergy, 1999, 29(Suppl 2):53-8.

17. Zhai Jia,Zou Yingxue, Guo Yongsheng. Logistic Regression Analysis for Detecting the Risk Factors for Infants Recurrent Wheezing.[J] .J Med Theor $\otimes$ Prac,2018, 31ه1区.

18. Matricardi $P$ M,Illi S,Grüber $C$ et al. Wheezing in childhood: incidence, longitudinal patterns and factors predicting persistence.[J] .Eur. Respir. J., 2008, 32: 585-92.

19. Guo Jing,Zhu Wenjing,Wang Huimin et al. Risk factors and prognosis of recurrent wheezing in Chinese young children: a prospective cohort study.[J] .Allergy Asthma Clin Immunol, 2019, 15: 38. 
20. Fu Liang,Freishtat Robert J,Gordish-Dressman Heather et al. Natural progression of childhood asthma symptoms and strong influence of sex and puberty.[J] .Ann Am Thorac Soc, 2014, 11: 93944. 